\title{
EVALUATION OF ANTI-GLYCATION EFFECT AND SAFETY OF SERUM ANTI-AGING FORMULATION CONTAINING GOLD NANOPARTICLES (AUNP) USING SIDAGURI EXTRACT (SIDA RHOMBIFOLIA)
}

\section{DYAH AYUWATI WALUYO, SUTRIYO}

\author{
Faculty of Pharmacy, Universitas Indonesia, Depok, 16424, West Java, Indonesia
}

Email: sutriyo@farmasi.ui.ac.id

Received: 01 Dec 2020, Revised and Accepted: 29 Oct 2021

ABSTRACT

Objective: The purpose of this study is to determine the anti-aging properties and safety of serum containing gold nanoparticles (AuNP) using Sidaguri extract (Sida rhombifolia) through their anti-glycation effect.

Methods: The anti-aging effect of serum was performed in vitro by measuring advance glycation end products (AGEs) formed during incubation using a Microplate reader, and safety of serum was performed using hen's egg chorioallantoic membrane (HET-CAM) method using White Leghorn egg

Results: The study showed that serum formulation had an anti-glycation effect with inhibition percentages are $68.20 \pm 6.86 \%$ and $74.83 \% \pm 19.91 \%$ for a serum containing $10 \%$ and $20 \%$ gold nanoparticles and little to no irritation potency for both serum formulations with RI value 0.0 and 0.0 , respectively.

Conclusion: Due to both their anti-glycation effect and irritation behavior, serum formulation containing gold nanoparticle synthesized using Sidaguri extracts could be utilized as anti-aging cosmetics in the future.

Keywords: Gold nanoparticle, Sidaguri extract, Glycation, HET-CAM, Safety

(C) 2022 The Authors. Published by Innovare Academic Sciences Pvt Ltd. This is an open access article under the CC BY license (https://creativecommons.org/licenses/by/4.0/] DOI: https://dx.doi.org/10.22159/ijap.2022v14i1.40417. Journal homepage: https://innovareacademics.in/journals/index.php/ijap

\section{INTRODUCTION}

Aging is defined as accumulative damage that could lead to the cell, tissue, and organ disruption which happened progressively. This aging occurs in all organs, including the skin. One of the causes of skin aging is the presence of advance glycation end products (AGEs). Glycation reaction is a non-enzymatic reaction between reducing sugar and free amino acid in the protein resulting in AGEs production. The reduced free radical production could inhibited AGEs in the initial phase by reducing free radical production to reduce the formation of carbonyl or dicarbonyl groups, blocking in the propagation phase by blocking the dicarbonyl or carbonyl groups of sugar, and detoxification of reactive dicarbonyl metabolite [1].

AuNP is one of the anti-glycation agents that inhibit AGEs production by competitively binding reducing sugar in binding free amino groups of lysine and arginine that are important for glycation. By this description, AuNP could be categorized as an anti-glycation agent that inhibits in the initial phase [2]. The ability of AuNP had been proven scientifically. The gold nanoparticle has an antiglycation activity on collagen as much as $56.3 \pm 4.2 \%$ compared to Aminoguanidin 64.0 5 5.7\% [2]. AuNP synthesized using Sidaguri extract, resulting in $83.372 \%$ inhibition activity compared to aminoguanidine that has $79.793 \%$ inhibition activity [3]. AuNP is considered to be an anti-aging agent on cosmetics due to its antiglycation activity.

AuNP could be synthetized using plant extract (green synthesis method). The advantages of green synthesis are relatively safe for the environment, reproducible, and cost-effective, and more stable product material [4]. Green synthesis has been performed using plant extract, vitamins, biodegradable polymers, microorganisms [4]. In extract plants, the ability to synthesize nanoparticle is due to their ability to reduce metal ions. Their reductive capacity relied on the hyper accumulating and reductive capacity. Flavonoid could undergo tautomeric transformation to the keto-form; this leads to releasing the reactive hydrogen atom that important to reduce metal ions in gold nanoparticle from $\mathrm{Au}_{3}{ }^{+}$ion to $\mathrm{Au}$ [5]. Sidaguri is one of the wild plants found massively in a tropical environment, including
Indonesia. Sidaguri has a reduction capability due to its antioxidant activity [6]. The availability and the content lead to the usage of Sidaguri extract to synthesize gold nanoparticles.

In this study, gold nanoparticle was synthetized using Sidaguri extracts and formulated into the serum, subjected to an in vitro antiglycation test and irritancy test. An anti-glycation test was performed to optimize the formulation dose by observing the ability of serum formulation to inhibit AGEs formed during the test Meanwhile, the irritancy test was performed using the HET-CAM test to classify further the material based on its irritancy characteristics.

\section{MATERIALS AND METHODS}

\section{Material and chemicals}

Material used during the study are Gold nanoparticle synthesize using Sidaguri extract, Xanthan Gum (Deosen Biochemical (Ordos) Ltd., China), Phenoxyethanol, Glycerin (Palm-Oleo Sdn, Malaysia), Bovine Serum Albumin (BSA) (Sigma Aldrich, Inggris), Fructose (Merck, Germany), Phosphate Buffer Saline (Merck, Germany), Sodium Azide (Merck, Germany), Aminoguanidine $\mathrm{HCl}$ (Shandong Zhi Shang Chemical, China), White Leghorn Egg (Balitnak, Indonesia), Sodium Chloride 0.9\% (B. Braun, Malaysia), Sodium hydroxide, distilled water and double distilled water.

The tools used are analytical weigh, Ika Eurostar High Speed Mixer (IMMlab, Prancis), pHmeter (Eutetech Instrument, Singapore), Microplate reader GloMax (Promega Corporation, Madison, WI, USA), Micropippette (Eppendorf), 96 well plate (Costar), Viscometer with spindle L3 and L4 (Cole Parmer, USA), hot plate and glassware.

\section{Serum anti-aging formulation}

AuNP was synthesized using Sidaguri extract; AuNP was prepared by reacting $\mathrm{HAuCl}_{4}$ and Sidaguri extract for $150 \mathrm{~min}$, then Sodium citrate for another minute. Then, the final product of AuNP was formulated into serum-containing xanthan gum as a thickening agent, phenoxyethanol as a preservative, and glycerine as a humectant 
Firstly, the serum base was optimized by varying the concentration of xanthan gum, as listed in table 1 . The serum was prepared by dispersing xanthan gum to the third-quarter volume of distilled water used and let the xanthan gum out until a transparent film was formed. Then, glycerine and phenoxyethanol were added into the gel, and the mixture was stirred with a mixer at $1000 \mathrm{rpm}$ until a homogeneous mixture obtained while adding the remaining distilled water. The serum base was evaluated its organoleptic, $\mathrm{pH}$, viscosity, and homogeneity.

Table 1: Formula of anti-aging serum base

\begin{tabular}{llll}
\hline Material & Formula $(\% \mathbf{w} / \mathbf{w})$ & & F3 \\
\cline { 2 - 4 } & F1 & F2 & 1.00 \\
\hline Xanthan Gum & 0.50 & 0.75 & 3.00 \\
Glycerin & 3.00 & 3.00 & 0.80 \\
Phenoxyethanol & 0.80 & 0.80 & Up to 100 \\
Distilled water & Up to 100 & Up to 100 & \\
\hline
\end{tabular}

After optimizing the serum bases, two concentrations of AuNP were added to the optimized serum bases as listed in table 2. The two formulas have tested the activity against AGEs formation using anti-glycation test.

Table 2: Formula of serum anti-aging containing AuNP

\begin{tabular}{lll}
\hline Material & Formula (\%w/w) & \\
\cline { 2 - 3 } & F2.1 & F2.2 \\
\hline AuNP & 10 & 20 \\
Serum base & Up to 100 & Up to 100 \\
\hline
\end{tabular}

\section{Anti-glycation test}

The dosage of AuNP used in serum was optimized using an antiglycation test. This study used a modifications of methods by Spinola and Sutriyo $[3,7]$. The sample used in this test is Aminoguanidine $\mathrm{HCl}$, serum formulation containing 10\% AuNP (F2.1) and serum containing 20\% AuNP (F2.2).

There are two solutions prepared, a test and a blank solution. The differences between these two solutions are the blank solution did not contain fructose $0.5 \mathrm{M}$. The test solution was prepared by mixing $50 \mu \mathrm{l}$ Bovine Serum Albumin $10 \mathrm{mg} / \mathrm{ml}$ (BSA), $50 \mu \mathrm{l}$ fructose $0.5 \mathrm{M}$, $80 \mu \mathrm{l}$ phosphate buffer saline (PBS) pH 7.4 containing $0.2 \%$ sodium azide $\left(\mathrm{NaN}_{3}\right)$ and $20 \mu \mathrm{l}$ of a sample in the microplate. A blank solution was prepared by mixing $50 \mu \mathrm{l}$ Bovine Serum Albumin 10 $\mathrm{mg} / \mathrm{l}$ (BSA), $80 \mu \mathrm{l}$ phosphate buffer saline (PBS) pH 7.4 containing $0.2 \%$ Natrium Azide $\left(\mathrm{NaN}_{3}\right)$, and $20 \mu \mathrm{l}$ of a sample in the microplate.

Then, the microplate was incubated at $37^{\circ} \mathrm{C}$ for seven days. The intensity of each mixture was analyzed using a microplate reader by measuring the intensity of the fluorescent at 415-445 nm emission and $365 \mathrm{~nm}$ excitation. The percentage of inhibition was calculated using equation 1 [7]. All test and the blank solution was prepared Duplo or triple.

$$
\text { \%inhibisi }=\frac{\left(F_{c}-F_{c b}\right)-\left(F_{s}-F_{s b}\right)}{\left(F_{c}-F_{c b}\right)} x 100 \%
$$

Fc: The fluorescence intensity of the negative control solution

Fcb: The fluorescence intensity of the negative control's blank solution

Fs: The fluorescence intensity of the test solution

Fsb: The fluorescence intensity of the sample test's blank solution

\section{Irritancy test using HET-CAM method}

HET-CAM method performed using fertile chicken eggs from White Leghorn species. Eggs used must be fresh (stored no longer than seven days) with a weight range of 45-70 grams. The eggs should be washed thoroughly, then incubated until day eight after laid at temperature $37.8 \pm 0.3{ }^{\circ} \mathrm{C}$. The eggs were placed with CAM membrane in the top position, and the eggs must be rotated $180^{\circ}$ every day. On day 8 , the eggs were checked using candling light to separate the fertile and sterile egg. On day 9, the fertile eggs were tested with the sample test.

The eggs were divided into five groups of treatment. Group 1 was given $\mathrm{NaCl} 0.9 \%$ (negative control), group 2 was given with $\mathrm{NaOH}$ $0.1 \mathrm{~N}$ (positive control), group 3 was given serum base, group 4 was given serum containing $10 \%$ AuNP, and group 5 was given serum containing 20\% AuNP.

As much as $0.3 \mathrm{ml}$ sample test was applied to CAM membrane. After sample test application, the time of hemorrhage, lysis, and coagulation occurred will be noted $[8,9]$. Irritation index (RI) will be calculated using equation 2 , then the mean of RI will be used to determine the irritancy level of testing material. Irritation classification could be seen in table 2 .

$$
R I=\frac{301-\sec H}{300} \times 5+\frac{301-\sec L}{300} \times 7+\frac{301-\sec C}{300} \times 9
$$

Sec H: time when hemorrhage happened (in seconds)

Sec L: time when lysis happened (in seconds)

Sec C: time when coagulation happened (in seconds)

Table 3: Material irritation classification

\begin{tabular}{ll}
\hline Irritation index (RI value) & Material classification \\
\hline $0-0.9$ & Non-irritant \\
$1-4.9$ & Weak to little irritant \\
$5-8.9$ & Medium irritant \\
$9-21$ & Strong to severe irritant \\
\hline
\end{tabular}

[source: [10]

\section{RESULTS}

\section{Serum formulation}

The obtained serum base had a clear gel-like cosmetic form and was found to be homogenous on all formula. The differences in xanthan gum influence $\mathrm{pH}$ and obtained viscosity. Viscosity obtained for formula F3 was measured with different spindle due to the stark differences in viscosity with F1 and F2 that has less viscous. F3 was measured with spindle L3; meanwhile F1 and F2 were measured with spindle L4. All serum formulation evaluation result could be seen in table 3. Based on the appearances and consistency, the considered formula was formula F1 and F3.

Table 4: Physical evaluation of serum base

\begin{tabular}{llll}
\hline Formula & Homogeneity & pH & Viscosity (at 30 rpm) \\
\hline F1 & Homogenous & 6.94 & $2019.53 \mathrm{cps}(\mathrm{L} 3)$ \\
F2 & Homogenous & 6.71 & $3014.33 \mathrm{cps}(\mathrm{L3})$ \\
F3 & Homogenous & 6.50 & $5508.77 \mathrm{cps}(\mathrm{L} 4)$ \\
\hline
\end{tabular}

Note: Data given in mean $\pm S D, n=3$ 


\section{Anti-glycation test}

Glycation inhibition activity for formula 10\% (F2.1) are $68.20 \pm 6.86 \%$ meanwhile formula $20 \%$ (F2.2) resulting $74.83 \pm 19.91 \%$ inhibition with the positive control are $39.09 \pm 11.67 \%$, raw data could be seen at table 5 .
Based on the statistical calculation, both formulas resulting in a significantly better inhibition activity $(\mathrm{p}<0.05)$ than the positive control. However, the comparison between formula 10\% (F2.1) and formula $20 \%$ (F2.2) was not significantly different. Based on the comparison, optimized dosage used for serum formulation was $10 \%$ (F2.1).

Table 5: Fluorescence intensity of anti-glycation activity test

\begin{tabular}{lll}
\hline Sample & Fluorescence intensity \\
\cline { 2 - 3 } & I & II \\
\hline Negative control (test) & 662 & 662.3 \\
Negative control (blank) & 200.4 & 249 \\
Positive control (test) & 324.9 & 349.6 \\
Positive control (blank) & 99.2 & 116.3 \\
Formula 2.1 (test) & 244.9 & 230.8 \\
Formula 2.1 (blank) & 134.6 & 363.8 \\
Formula 2.2 (test) & 693.4 & 120.1 \\
Formula 2.2 (blank) & 696.5 & 236.1 \\
\hline
\end{tabular}

Note: Data given as shown on the microplate reader

\section{Glycation Inhibition Activity}

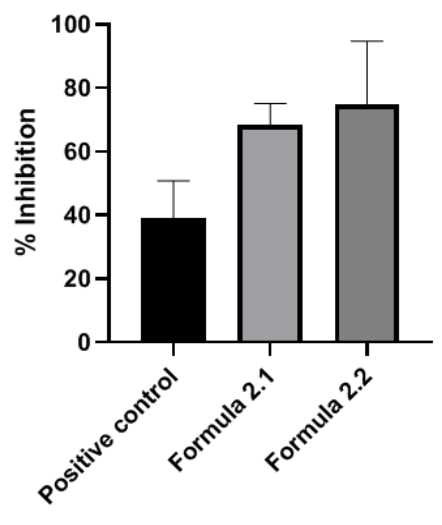

Test Sample

Fig. 1: Result of anti-glycation test

Note: Data shown as mean $\pm S D, n=81$ (positive control, formula 2.2); $n=54$ (formula 2.1)

Irritation test using HET-CAM test

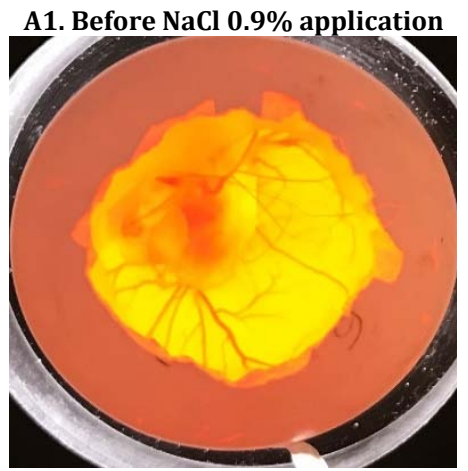

B1. Before $\mathrm{NaOH}$ application

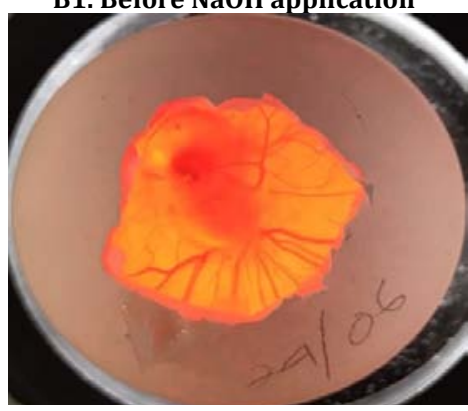

A2. After $\mathrm{NaCl}$ 0.9\% application

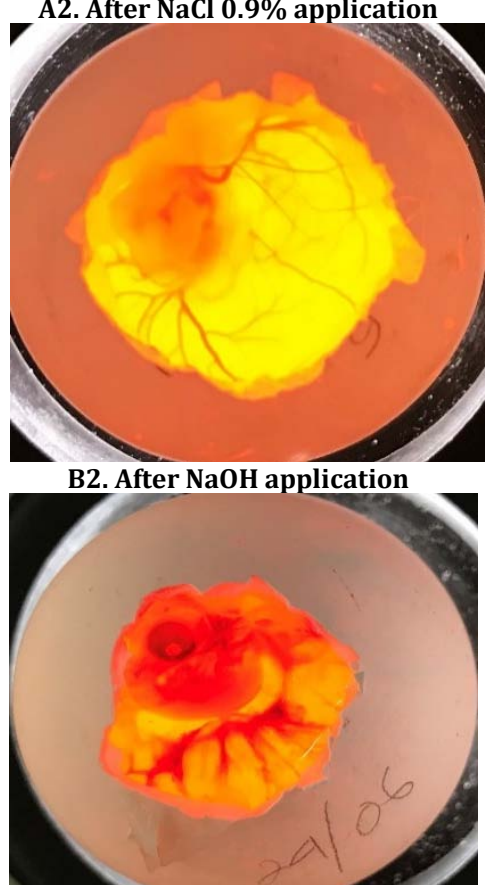



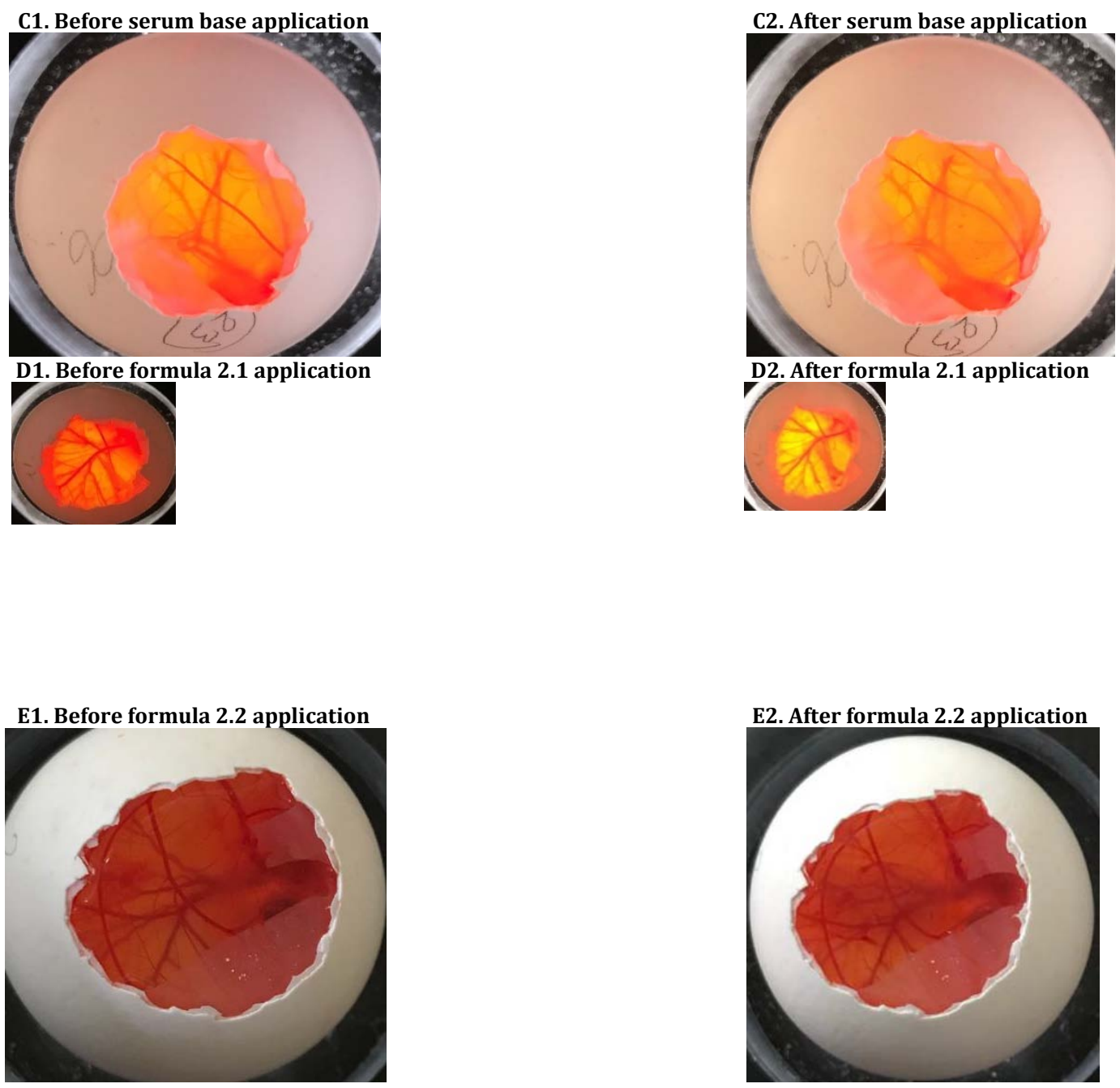

Fig. 2: Images of the egg during the HET-CAM test

There was no hemorrhage, lysis, and coagulation formed on the egg's CAM in groups 1,3,4, and 5. Hemorrhage, lysis, and coagulation were found in group 2, positive control. Hemorrhage formed on averagely the first $12 \mathrm{~s}$, followed by lysis of blood vessel around 80 120 s and coagulation formed was varied on 200-300s (fig 2. B2). All results of eye irritant potency could be seen in table 6 and fig. 2 .

Table 6: Result of irritant test

\begin{tabular}{lll}
\hline Test solution & Irritation score (Mean) & Irritant classification \\
\hline $\mathrm{NaOH} 0.9 \%$ (negative control) & $0.0 \pm 0.00$ & Non-irritant \\
$\mathrm{NaOH} \mathrm{0.1} \mathrm{N} \mathrm{(positive} \mathrm{control)}$ & $12.408 \pm 1.28$ & Strong to severe irritant \\
Serum base & $0.0 \pm 0.00$ & Non-irritant \\
Serum containing 10\% AuNP & $0.0 \pm 0.00$ & Non-irritant \\
Serum containing 20\% AuNP & $0.0 \pm 0.00$ & Non-irritant \\
\hline
\end{tabular}

Note: data given in mean $\pm \mathrm{SD}, \mathrm{n}=4$

\section{DISCUSSION}

AuNP was formulized into serum due to its high concentration than other cosmetics forms $[11,12]$. The advantages of serum are easy and comfortable to use because of the minimum oil phase [13]. In this study, xanthan gum was used as a thickening agent due to its pseudoplasticity characteristics so that the cosmetics would become smooth and soft [14]. Xanthan is non-toxic, not irritating when applied to the skin, and stable over extensive range of $\mathrm{pH}$ values [15]. A low concentration of xanthan gum in an aqueous solution is highly viscous and stable in changes of heat, $\mathrm{pH}$, and resistance to enzymatic degradation due to its structural rigidity [14].

F1 and F2 have almost the same appearances, however, F1 was less viscous. Therefore, we considered using the F2 due to the API
(AuNP) liquid form and anticipating the final product not too watery, and the F2 was selected.

AGEs are glycation reaction product derived from a non-enzymatic reaction between sugar and free amino acid in the protein. Based on AGEs' chemical characteristics, AGEs could be classified into noncross-linking and cross-linking. The cross-linking AGEs could be classified into fluorescent and non-fluorescent ones [16]. The inhibition mechanism of AGE synthesis could only delay or reduce AGE formation [1]. Aminoguanidine is one of the anti-glycation agents that usually used as a positive control during the antiglycation inhibition activity test. Aminoguanidine limited AGEs' formation by trapping products from early glycation, such as intermediate carbonyl compound [17]. 
Bovine serum albumin (BSA)-fructose test was one method used for detecting AGEs formed by measuring fluorescence intensity at emission and excitation wavelengths of 415-445 and $365 \mathrm{~nm}$ [18]. Then as mentioned before, bovine serum albumin will be acting as a model protein and fructose as the glycation agent. The condition chosen for the incubation process was similar to the normal human body $\left(37^{\circ} \mathrm{C}, \mathrm{pH} 7.4\right)$. To create $\mathrm{pH} 7.4$ condition, PBS was added into the mixture. $\mathrm{NaN}_{3}$ was added to the PBS solution to prevent yeast from growing during the incubation process. During incubation, the plate shall be covered with aluminium foil to prevent the mixture from dried. Incubation for seven days of the mixture was expected to produce fluorescent AGEs detected using a microplate reader [19]. Theoretically, the sample solution will result in higher intensity than the blank sample due to there is little to no AGEs formation reaction in the blank. In pre-studies, gold nanoparticle synthesized with Sidaguri extract had been proven AuNP has higher inhibition activity, $83.87 \pm 4.39 \%$, than Aminoguanidine, $79.79 \pm 3.20 \%$, and there is a significant difference in their inhibition activity [3].

HET-CAM test is used to classify material that is expected to be nonirritant or mildly irritant. HET-CAM evaluates the conjunctiva part of the eye $[9,20]$. In this research, serum AuNP was predicted to be non-irritant material; therefore usage of HET-CAM for eye irritation test was performed. HET-CAM test principle observes and measures hemorrhage, lysis, and coagulation effects on the CAM when sample test applied, the test used was using RTM (Reaction Time Method) [9]. Tests were performed on day-9 when nerve tissue and pain perception have not yet been formed [20].

Based on ICCVAM guidelines, the HET-CAM test is acceptable if the RI value of $0.9 \% \mathrm{NaCl}$ as a negative control was 0.0 and the RI value of $0.1 \mathrm{~N} \mathrm{NaOH}$ as a positive control was ranged between 10 and 19 . In this experiment, all this requirement was met. RI value of $0.9 \%$ $\mathrm{NaCl}$ was 0 and RI value of $0.1 \mathrm{~N} \mathrm{NaOH}$ was 12.408 . Thus, both serum base and serum-containing AuNP could be presumed non-irritant to the eye with an RI value 0.0 .

\section{CONCLUSION}

Serum anti-aging containing AuNP synthesized using Sidaguri extract has high anti-glycation activity compared to the positive control with dose optimized at $10 \%$. Then, serum-containing AuNP synthesized with Sidaguri extract is a little to no irritant material. Considering the in vitro activity and safety, AuNP synthesized from Sidaguri extract could be considered to use as anti-aging cosmetics. However, the anti-aging activity and eye irritation characteristic of AuNP needs further study.

\section{ACKNOWLEDGMENT}

Universitas Indonesia supported this work via PUTI SAINTEKES Q4 No. NKB-2087/UN2. RST/HKP.05.00/2020 Grant program.

\section{FUNDING}

Nil

\section{AUTHORS CONTRIBUTIONS}

All authors have contributed equally.

\section{CONFLICT OF INTERESTS}

Declared none

\section{REFERENCES}

1. Yeh WJ, Hsia SM, Lee WH, Wu CH. Polyphenols with antiglycation activity and mechanisms of action: a review of recent findings. J Food Drug Anal. 2017;25(1):84-92. doi: 10.1016/j.jfda.2016.10.017, PMID 28911546.

2. Kim JH, Hong CO, Koo YC, Choi HD, Lee KW. Anti-glycation effect of gold nanoparticles on collagen. Biol Pharm Bull. 2012;35(2):260-4. doi: 10.1248/bpb.35.260, PMID 22293359.

3. Idris PK, Sutriyo. Antiglycation effect of green synthesized gold nanoparticle using Sidaguri extract (Sida rhombifolia L.) as antiaging therapies. [Depok (Indonesia)]. Universitas Indonesia; 2019.

4. Teimuri Mofrad R, Hadi R, Tahmasebi B, Farhoudian S, Mehravar M, Nasiri R. Green synthesis of gold nanoparticles using plant extract: mini-review. Nanochem Res. 2017;2:8-17.

5. Makarov VV, Love AJ, Sinitsyna OV, Makarova SS, Yaminsky IV, Taliansky ME, Kalinina NO. "Green" nanotechnologies: synthesis of metal nanoparticles using plants. Acta Nat. 2014;6(1):35-44. doi: 10.32607/20758251-2014-6-1-35-44. PMID 24772325.

6. Dhalwal K, Deshpande YS, Purohit AP. Evaluation of in vitro antioxidant activity of Sida rhombifolia (L.) ssp. retusa (L.). J Med Food. 2007;10(4):683-8. doi: 10.1089/jmf.2006.129, PMID 18158841.

7. Spínola V, Pinto J, Castilho PC. Hypoglycemic, anti-glycation and antioxidant in vitro properties of two Vaccinium species from Macaronesia: a relation to their phenolic composition. J Funct Foods. 2018;40:595-605. doi: 10.1016/j.jff.2017.12.002.

8. Steiling W, Bracher M, Courtellemont P, de Silva O. The HET-CAM, a useful in vitro assay for assessing the eye irritation properties of cosmetic formulations and ingredients. Toxicol In Vitro. 1999;13(2):375-84. doi: 10.1016/s0887-2333(98)00091-5. PMID 20654494.

9. Scheel J, Kleber M, Kreutz J, Lehringer E, Mehling A, Reisinger K, Steiling W. Eye irritation potential: usefulness of the HET-CAM under the globally harmonized system of classification and labeling of chemicals (GHS). Regul Toxicol Pharmacol. 2011;59(3):471-92. doi: 10.1016/j.yrtph.2011.02.003, PMID 21310206.

10. Sahu RK, Singh B, Saraf SA, Kaithwas G, Kishor K. Photochemical toxicity of drugs intended for ocular use. Arh Hig Rada Toksikol. 2014;65(2):157-67. doi: 10.2478/100041254-65-2014-2461, PMID 24846953.

11. Mardiyanti S. Formulasi serum menggunakan serbuk konsentrat ikan gabus (Channa striatus) sebagai penyembuh luka bakar. [Depok (Indonesia]: Universitas Indonesia; 2016.

12. Sashidaran S, Joseph P, Junise. Formulation and evaluation of fairness serum using polyherbal extracts. Int J Pharm. 2014;4:105-12.

13. Draelos. Cosmetics and dermatological problems and solutions. London, UK: Informa Healthcare; 2016.

14. Rahman IMM, Begum ZA, Yahya S, Lisar S, Motafakkerazad R, Cell AS-P. Xanthan gum-applications and research studies. Hauppauge, (NY): Nova Science Publishers, Inc; 2016.

15. Roes Lie ISR, Djajadisastra J, Saputri FC. Green tea extract in an eyelash growth enhancer gel formulation: stability test, eye irritation test, and human eyelash growth activity. Asian J Pharm Clin Res. 2017;10(6):243-6. doi: 10.22159/ajpcr.2017.v10i6.18605.

16. Villa M, Parravano M, Micheli A, Gaddini L, Matteucci A, Mallozzi C, Facchiano F, Malchiodi Albedi F, Pricci F. A quick, simple method for detecting circulating fluorescent advanced glycation end-products: correlation with in vitro and in vivo non-enzymatic glycation. Metabolism. 2017;71:64-9. doi: 10.1016/j.metabol.2017.03.004, PMID 28521879.

17. Gkogkolou P, Böhm M. Advanced glycation end products: keyplayers in skin aging? Dermatoendocrinol. 2012;4(3):25970. doi: 10.4161/derm.22028, PMID 23467327.

18. Julius A, Hopper W. Inhibition of advanced glycation endproduct formation by quercetin and catechin: an alternative therapy for treating diabetic complications. Asian J Pharm Clin Res. 2017;10(11):173-6. doi 10.22159/ajpcr.2017.v10i11.19412.

19. Grzegorczyk Karolak I, Gołąb K, Gburek J, Wysokinska H, Matkowski A. Inhibition of advanced glycation end-product formation and antioxidant activity by extracts and polyphenols from Scutellaria alpina L. and S. altissima L. Molecules. 2016;21(6):1-10. doi: 10.3390/molecules21060739, PMID 27314314.

20. Derouiche MTT, Abdennour S. HET-CAM test. Application to shampoos in developing countries. Toxicol In Vitro. 2017;45(3):393-6. doi: 10.1016/j.tiv.2017.05.024. PMID 28602853. 